\title{
Comparative analysis of Klebsiella pneumoniae genomes identifies a phospholipase D family protein as a novel virulence factor
}

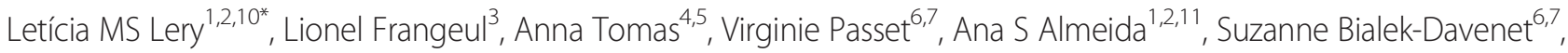
Valérie Barbe ${ }^{8}$, José A Bengoechea ${ }^{4,5,12}$, Philippe Sansonetti ${ }^{1,2,9}$, Sylvain Brisse ${ }^{6,7}$ and Régis Tournebize ${ }^{1,2,13^{*}}$

\begin{abstract}
Background: Klebsiella pneumoniae strains are pathogenic to animals and humans, in which they are both a frequent cause of nosocomial infections and a re-emerging cause of severe community-acquired infections. K. pneumoniae isolates of the capsular serotype K2 are among the most virulent. In order to identify novel putative virulence factors that may account for the severity of K2 infections, the genome sequence of the K2 reference strain Kp52.145 was determined and compared to two K1 and K2 strains of low virulence and to the reference strains MGH 78578 and NTUH-K2044.
\end{abstract}

Results: In addition to diverse functions related to host colonization and virulence encoded in genomic regions common to the four strains, four genomic islands specific for Kp52.145 were identified. These regions encoded genes for the synthesis of colibactin toxin, a putative cytotoxin outer membrane protein, secretion systems, nucleases and eukaryotic-like proteins. In addition, an insertion within a type VI secretion system locus included sel1 domain containing proteins and a phospholipase D family protein (PLD1). The pld1 mutant was avirulent in a pneumonia model in mouse. The pld1 mRNA was expressed in vivo and the pld1 gene was associated with K. pneumoniae isolates from severe infections. Analysis of lipid composition of a defective $E$. coli strain complemented with pld 1 suggests an involvement of PLD1 in cardiolipin metabolism.

Conclusions: Determination of the complete genome of the K2 reference strain identified several genomic islands comprising putative elements of pathogenicity. The role of PLD1 in pathogenesis was demonstrated for the first time and suggests that lipid metabolism is a novel virulence mechanism of K. pneumoniae.

Keywords: Genome sequencing, Host-microbe interactions, Bacterial pathogenesis, Lipid metabolism

\section{Background}

Klebsiella pneumoniae is responsible for a variety of diseases in humans and animals. As a prominent nosocomial pathogen it is mainly responsible for urinary tract, respiratory tract or blood infections [1-3]. In addition, because of the acquisition of extended-spectrum $\beta$-lactamases and carbapenemases, such as the recently described NDM-1 [4], multi, extremely or pan-drug resistant clinical strains are more frequently isolated $[5,6]$. In addition, $K$. pneumoniae has re-emerged as a cause of community-acquired infections including pneumonia and the characteristic

\footnotetext{
* Correspondence: Ilery@biof.ufrj.br; regis.tournebize@pasteur.fr

${ }^{1}$ Institut Pasteur - Pathogénie Microbienne Moléculaire, Paris, France

2INSERM U786, Paris, France

Full list of author information is available at the end of the article
}

syndrome of pyogenic liver abscess, with possible complications including endophthalmitis or meningitis $[7,8]$. $K$. pneumoniae is, thus, an important virulent pathogen able to cause serious infections in ambulatory, otherwise healthy hosts and to spread within patients $[5,9]$ that requires a better understanding of the molecular mechanisms underlying the various forms of its pathogenesis.

Major $K$. pneumoniae virulence factors include the capsule, the lipopolysaccharide, iron scavenging systems and adhesins [3,10-14]. The capsule is one of the most important virulence determinants, protecting against serum bactericidal activity, antimicrobial peptides and phagocytosis [11,15-18]. At least 77 capsular (K) types can be distinguished, but types $\mathrm{K} 1$ and $\mathrm{K} 2$ are prominent 
by their virulence in murine models of infection [19-21] and by their epidemiological prevalence $[9,18,21,22]$. However, not all K1/K2-type strains are necessarily virulent, as distinct clonal groups of $\mathrm{K} 1$ and $\mathrm{K} 2$ differ sharply by their virulence [23]. Reference strain Kp52.145 (derived from B5055, the reference strain of serotype K2) is a highly virulent strain from which important virulence factors, including the large virulence plasmid harboring the regulator of mucoid phenotype $(r m p A)$ and the aerobactin cluster, were identified $[10,11,21]$. Even though a virulence plasmid-cured strain is less virulent than the parental strain, it remained more virulent than other isolates that do not harbor this plasmid [21], showing that factors other than capsule overexpression and aerobactin account for the higher pathogenesis of this strain. Therefore, although known virulence factors are certainly crucial for bacterial survival, protection and interaction with the host, putative new virulence factors that could subvert host cell physiology and response remain yet to be identified.

Comparative genomics of pathogenic and non-pathogenic strains is a powerful approach to identify putative virulence genes. Several draft or complete genomes of clinical isolates of K. pneumoniae have been published so far, but only the virulent serotype K1 strain NTUH-K2044 [24] has been described in detail. In order to identify new $K$. pneumoniae $\mathrm{K} 2$ virulence factors, we sequenced the genome of the virulent strain Kp52.145, as well as two additional strains of low virulence, SB2390 (serotype K2) and SB3193 (serotype K1). By comparing these three novel genomes to the publicly available genomes of the virulent K1 strain NTUH-K2044 and reference strain MGH 78578, we identified in Kp52.145 putative virulence genes and analyzed their distribution within a diverse collection of $K$. pneumoniae strains. We demonstrate that a gene coding for a phospholipase D family protein (PLD1), located within a type VI secretion system locus, is expressed in vivo, is involved in controlling bacterial membrane lipid composition, and is a new virulence factor.

\section{Results and Discussion}

\section{Genome assembly and annotation}

The genomes of Kp52.145, SB2390 and SB3193 were sequenced by a combination of 454 and Illumina technologies using single and paired-end libraries. Finishing efforts resulted in the complete genome sequence of K. pneumoniae Kp52.145 (one chromosome + two plasmids), comprising 5.45 Mbp and 5,314 protein coding genes (Figure 1). SB2390 and SB3193 genomes were assembled in 11 and 17 scaffolds, respectively. The GC\% of these three genomes ranged from $55.6 \%$ to $56.7 \%$. The general features of the $K$. pneumoniae sequenced genomes are summarized in Table 1.

Because Kp52.145 is a highly virulent strain, our analyses were focused on comparing its genome with the genomes of K. pneumoniae strains SB2390, SB3193, NTUH-K2044 and MGH78578. According to SEED subsystems annotations [25], about $60 \%$ of protein-coding genes for each K. pneumoniae genome had predicted functions. More specifically, the largest percentage of annotated genes is involved in the metabolism of carbohydrates (approximately $20 \%$ ), of amino acids and their derivatives (approximately $10 \%)$ and of cofactors, vitamins and prosthetic groups (approximately 8\%) [see Additional file 1].

\section{Common genome}

To define the common genome of the five strains, we used stringent BlastClust parameters of at least $90 \%$ identity and at least $80 \%$ coverage. This analysis identified 3,587 coding sequences common to the five genomes. The majority of proteins are involved in metabolic processes, such as energy metabolism and transporters, supporting the general concept that the core genome encompasses essential functions required for survival of the microorganism. The $K$. pneumoniae core genome comprised several sets of genes whose functions are related to bacterial survival in the environment or interaction with its host, and possibly virulence. This was the case, for example, of genes involved in quorum-sensing and biofilm formation, adhesins, and secretion systems, for which examples are detailed below.

Genes encoding for autoinducer-2 and type III fimbria, involved in biofilm formation in K. pneumoniae [26-28], were present in all sequenced strains. In addition, genes coding for synthesis and transport of the poly- $\beta-1,6-\mathrm{N}$ acetyl-D-glucosamine (PGA) adhesin (KpST66_4915 to KpST66_4918 in Kp52.145 genome) which is required for the structural stability of Escherichia coli biofilms [29], and YidE (KpST66_0019), which mediates the hyperadherence phenotype of E. coli [30], were also found in the core genome of $K$. pneumoniae strains.

Moreover, the five $K$. pneumoniae genomes contained the genes barA/uvrY (respectively KPST66_0986 and KpST66_3517) and $y c j X / y c j F$ (KpST66_2441 and KpST66_2442) that may be involved in bacterial fitness and virulence. The two-component system BarA/UvrY (KpST66_3517 and KpST66_0986 in Kp52.145 genome) contributes to biofilm formation in Salmonella enterica and is a virulence determinant of urinary tract $E$. coli infections [31,32]. The E. coli YcjF protein is expressed in a septicemia murine model of infection in which the $y c j \mathrm{~F}$ mutant is attenuated, thus suggesting its implication in the in vivo survival/multiplication of the bacteria [33].

Several putative secretion systems were identified as part of the common genome of the K. pneumoniae strains, including one type I secretion system (T1SS) and one type II secretion system (T2SS). T2SS is composed of the pullulanase related genes pulA-O that are involved in the pathogenesis of several bacteria [34,35]. Streptococcus 


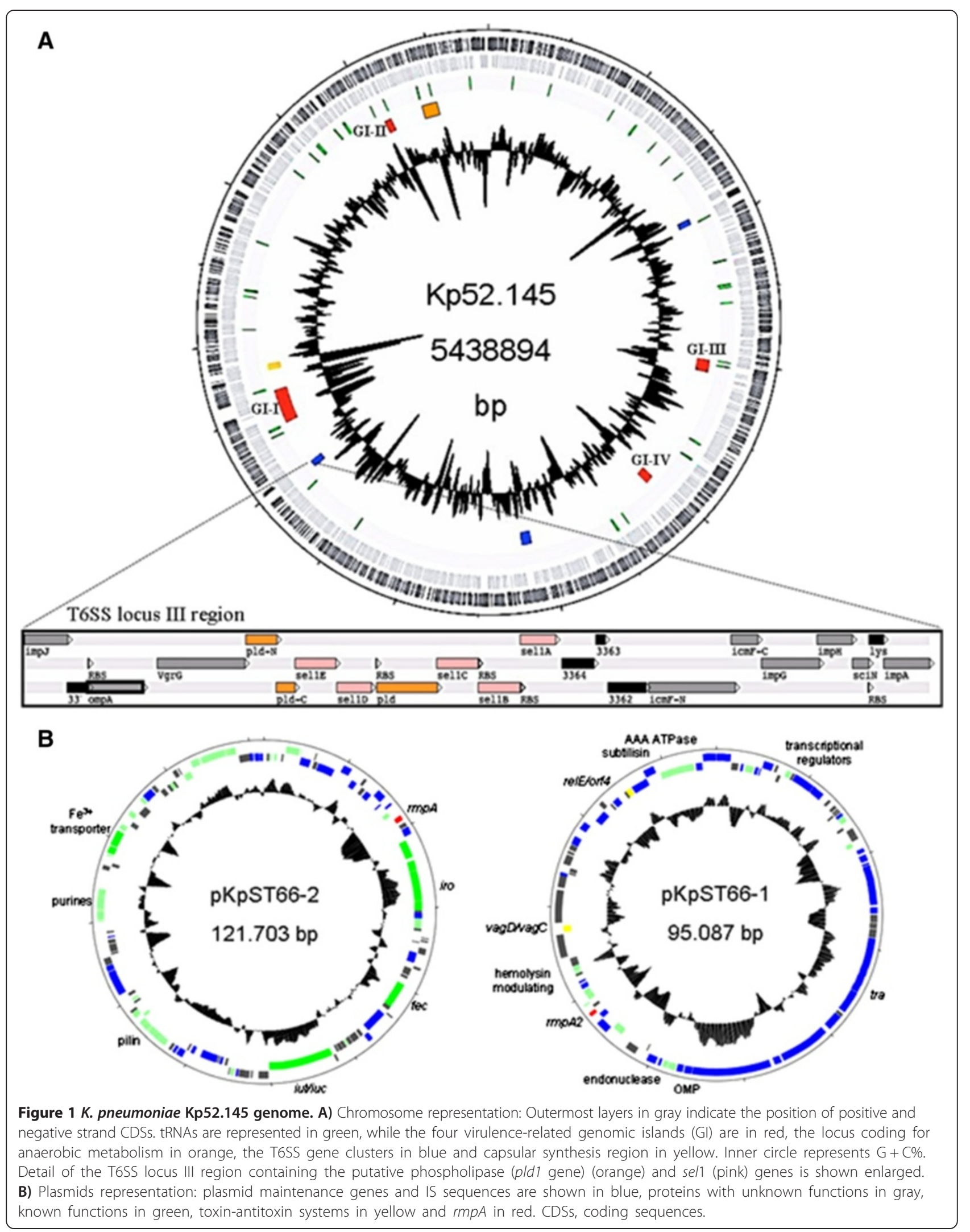


Table 1 General features of the $K$. pneumoniae genomes analyzed

\begin{tabular}{llccccccccc}
\hline K-type & Strain bank ID & Scaffolds & Size (Mb) & \% GC & Total PCG & rRNA operons & tRNA genes & \% coding & Plasmids & Reference \\
\hline K2 & $3341 /$ Kp52.145 & 3 & 5.45 & 56.4 & 5,314 & 8 & 85 & 88 & 2 & This manuscript \\
K2 & 2390 & 11 & 5.62 & 56.74 & 5,367 & 6 & 77 & 86.8 & $?$ & This manuscript \\
K1 & 3193 & 16 & 5.01 & 55.6 & 4,793 & 10 & 73 & 92 & $?$ & This manuscript \\
K1 & NTUH (ST23) & 2 & 5.24 & 57.6 & 4,992 & 19 & 76 & 89 & 1 & Wu et al. [63] \\
K5 & MGH (SB107) & 6 & 5.31 & 57 & 4,776 & 10 & 56 & 85 & 5 & (NC_009648) \\
\hline
\end{tabular}

The three genomes sequenced in this study are compared to strains NTUH and MGH, previously published. PCG, protein coding genes.

pyogenes PulA binds to host lung glycogen leading to a strong interaction with alveolar type II cells [36]. Similarly, the alpha-amylase AmyA degrades glycogen into cyclic maltodextrins, which increases the transepithelial translocation of Streptococcus [37]. Both amyA and pulA-O genes are encoded in $K$. pneumoniae genomes, but their functions in this bacterium remain to be characterized. Type VI secretion system (T6SS) putative genes were located in at least three different loci of the K. pneumoniae genomes, in accordance with a previous in-silico study [38]. T6SS clusters are usually found within pathogenicity islands or on chromosomal regions presenting virulence or host survival biases. Additionally, T6SS has been suggested to assist colonization and infection. Indeed, in a screen that identified $K$. pneumoniae mutants failing to colonize mice [39], two of them were mutants in genes coding for proteins annotated as hypothetical, that have been subsequently re-annotated as T6SS proteins [38]. Type III secretion systems were not found in Klebsiella, but type IV secretion systems, possibly corresponding to conjugation apparatus, were present only in some strains (Kp52.145, SB2390 and NTUH-K2044) (Table 2).

Furthermore, the core genome presented a large genomic region located between gly-tRNA and phe-tRNA loci in Kp52.145 genome, containing frd $A B C D$ genes coding for the fumarate reductase enzymatic complex responsible for fumarate respiration under anaerobic growth of bacteria. This complex is a virulence determinant for Helicobacter pylori, Mycobacterium tuberculosis, Actinobacillus pleuropneumoniae and S. enterica, as mutants on these genes are attenuated [40-43]. The ability to grow anaerobically allows bacterial pathogens to persist in host tissues, including in the lungs. Curiously, this genomic locus encoded in $K$. pneumoniae at least one more protein involved in anaerobic metabolism, the anaerobic C4-dicarboxylate transporter DcuA (KpST66_4904), supporting the idea that this GI provides $K$. pneumoniae advantages to grow under anaerobic conditions, possibly favoring infection. Additional proteins that might be involved in bacterial fitness to environmental stress conditions were encoded in this region. For instance, the putative small multidrug resistance protein SugE (KpST66_4882) has been shown to regulate biofilm formation and capsule expression [44]. A lipocalin-2 bacterial protein $\mathrm{Bcl}$ (KpST66_4881) is also encoded in this island of the genome. Eukaryotic lipocalins are small extracellular proteins that bind hydrophobic ligands and fulfill numerous biological functions including regulation of

Table 2 Distribution of virulence-related factors among $K$. pneumoniae genomes analyzed

\begin{tabular}{|c|c|c|c|c|c|c|}
\hline Virulence-factor & SB3341 & SB2390 & SB3193 & NTUH & MGH & Functional role \\
\hline rmpA & ++ & - & - & ++ & - & Regulator of capsule expression \\
\hline Aerobactin & + & - & - & + & - & Siderophore \\
\hline Enterobactin & + & + & + & + & + & Siderophore \\
\hline Yersiniabactin & + & + & + & + & - & Siderophore \\
\hline Colibactin & + & - & - & - & - & Genotoxin \\
\hline T4SS (virB) & + & + & - & + & - & Conjugative machinery/protein secretion \\
\hline T2SS & + & + & + & + & + & Protein secretion \\
\hline T6SS & + & + & + & + & + & Protein secretion \\
\hline Pld-family & + & - & - & - & - & Lipid metabolism \\
\hline Sel1 lipoproteins & + & - & - & - & - & Unknown \\
\hline cOMP & + & - & - & - & - & Putative cytotoxin \\
\hline lgg-like & + & - & - & - & - & Binding to extra cellular matrix compounds \\
\hline SEFIR-domain & + & - & - & - & - & Potentially hijack IL17R signaling pathways \\
\hline $\mathrm{BCl}$ & + & + & - & + & + & $\begin{array}{l}\text { Binding to hydrophobic ligands / putative } \\
\text { regulation of homeostasis and immunity }\end{array}$ \\
\hline
\end{tabular}


cellular homeostasis and immunity and are regulators of antibacterial defense [45]. Lipocalin2 is for instance a siderophore scavenger for several bacteria, including $K$. pneumoniae [46], as well as a negative regulator of inflammatory response during Streptococcus pneumoniae pneumonia [47]. However, the role of bacterial lipocalins is not yet known.

Finally, a phosphatidylserine decarboxylase (KpST66_4873) might be important for the integrity of the bacterial membrane composition, as phospholipid biosynthetic pathways play crucial roles in the virulence of several pathogens $[48,49]$.

\section{Accessory genome}

The accessory genome (genes absent in at least one of the five strains) included a large number of specific coding sequences (CDSs): 743 genes were found only in Kp52.145, 608 in NTUH-K2044, 806 in SB3193, 635 in SB2390 and 488 in MGH78578. About 50\% of these genes code for hypothetical proteins or proteins of unknown function. The distribution of the putative virulencerelated genes of $K$. pneumoniae among the sequenced strains is summarized in Table 2. The specific regions or genes of Kp52.145 are detailed below.

\section{Kp52.145 plasmids}

Strain Kp52.145 possessed two plasmids (Figure 1B). The first plasmid of $121 \mathrm{~Kb}$ carried the aerobactin cluster and the regulator of mucoid phenotype rmpA genes. The presence of this plasmid was previously correlated with the virulence of K. pneumoniae $\mathrm{K} 1$ and $\mathrm{K} 2$ isolates [21,50]. Additionally, a strain cured from this plasmid showed a $6 \times 10^{4}$-fold reduction in virulence, establishing the link between this plasmid and bacterial virulence [21]. In addition to aerobactin and $r m p A$, this plasmid contained genes coding for F-pilin, purine metabolism, insertion sequences and proteins of unknown functions. Kp52.145 also carried a second, previously non-described, plasmid of about $90 \mathrm{~Kb}$. Interestingly, it contained rmpA2, a homologue of the regulator of mucoid phenotype $\operatorname{rmp} A$, which seems to be involved in capsule expression regulation [51,52]. F-pilin genes, a subtilisin-related serine protease, an AAA + ATPase, the UV protection system $\mathrm{UmuD} / \mathrm{UmuC}$ and the genes encoding the toxin-antitoxin systems RelE/orf4 and VagD/VagC (Figure 1B) were also found on this plasmid. However, the potential role of these genes in virulence remains to be investigated.

\section{Genomic islands identified in the genome of strain Kp52.145}

In addition to the capsule synthesis operon and the ironacquisition systems (yellow and orange boxes in Figure 1A, respectively), known to be involved in $K$. pneumoniae virulence, four additional regions of the Kp52.145 genome presented several characteristics of pathogenicity islands (red boxes, Figure 1A). These regions are defined by a different GC content in comparison to the average of the genome, represented large chromosomal regions (often $>30 \mathrm{~Kb}$ ), were associated with tRNA genes or with the presence of insertion sequences, integrases and transposases, and were present in pathogenic strains while less frequent in less-virulent strains [53,54]. The four GIs present in the Kp52.145 genome were present or partially present in NTUH, but none of them was present in SB2390, SB3193 and MGH 78578, indicating that their occurrence is specific to pathogenic genomes. Figure 2 shows the four GIs identified, highlighting the putative virulence related genes.

\section{Genomic island 1 (GI-1): ICE-Kp1-like region}

The largest GI found in the Kp52.145 genome comprised $133,679 \mathrm{bp}$, presented a GC content of $52 \%$, was inserted in an asn-tRNA locus and encoded 92 CDSs (Figure 2A). Most of the protein-coding genes found in this region were described as part of the IceKpI GI of NTUH-K2044 [55,56], although several differences were found. Kp52.145 GI-I begins at asn tRNA locus followed by several uncharacterized proteins and insertion sequence elements. GI-I coded for the synthesis of two polyketide/nonribosomal peptides (yersiniabactin and colibactin) and for the conjugative transfer machinery (T4SS) that allows horizontal transfer of the island [56]. In contrast to the previous description of IceKpI [56], the Kp52.145_GI-I carried colibactin and did not contain the region coding for vagCvagD, iroN-iroB-iroC-iroD and rmpA genes which are carried only by the $121 \mathrm{kB}$ plasmid in Kp52.145.

\section{Genomic island 2 (GI-II)}

We describe here a novel GI (GI-II). It is a 29,829 bp island, with a GC content of $49 \%$ and coding for 28 CDSs which is inserted in a leu-tRNA locus (Figure 2B). Potential pathogenesis-related genes coded for a putative cytotoxic outer membrane protein (cOMP, KpST66_4736) and a polyamine ABC transport system (KpST66_4729 to KpST66_4732). cOMP closest known homologue (34\% identity) was a Plesiomonas shigelloides predominant virulence factor proposed to trigger cell death in host cells following infection [57]. Polyamine biosynthesis and transport mechanisms were intricately linked to fitness, survival, biofilm formation and pathogenesis, for instance in S. pneumoniae and Yersinia pestis [58,59]. Additionally, this GI encoded a 4-phytase gene (KpST66_4736), ugpQ3 (KpST66_4728) and $x y l A, x y n T, x y n B, x y l R$ (KpST66_4724 to KpST66_4727) that are involved in xylose metabolism.

\section{Genomic island 3 (GI-III)}

The third GI is characterized by a 49,657 bp region presenting a $\mathrm{G}+\mathrm{C}$ content of $51 \%$ and contained $66 \mathrm{CDSs}$, 


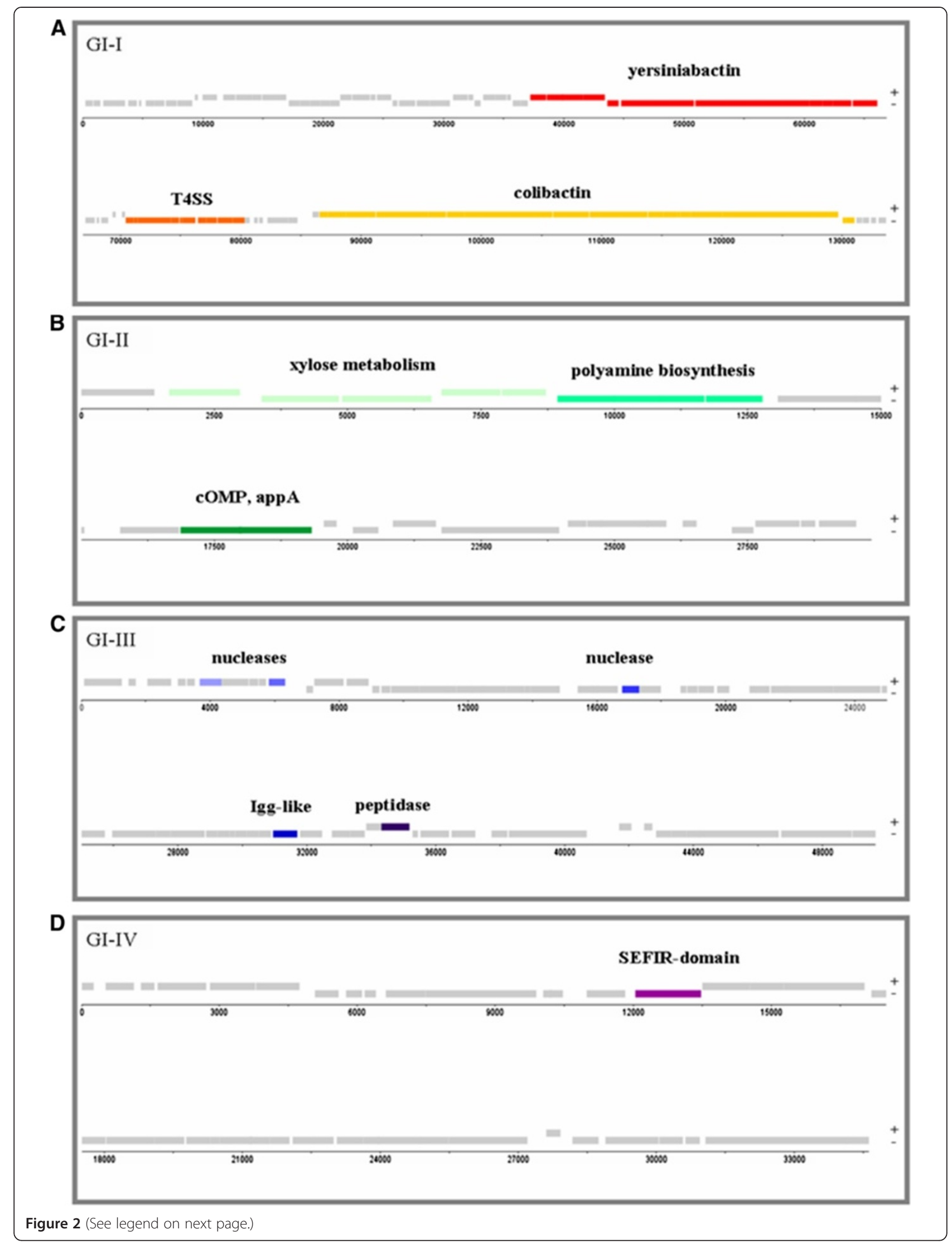


most of them coding for phage structural proteins (Figure 2C). This GI included genes coding for proteins with homologues that were shown to play a role in bacterial adhesion and immune system escape [60-62]. These proteins encoded for an immunoglobulin domaincontaining protein (KpST66_1506), a peptidase S24-like protein (KpST66_1511), two HNH family endonucleases (KpST66_1468 and 1486) and an exonuclease (locus 1464).

\section{Genomic island 4 (GI-IV)}

The forth island (GI-IV) was mainly comprised of phagerelated genes. Among the $42 \mathrm{CDSs}$ encoded within this genomic region, one gene coded for a SEFIR-domain containing protein (KpST66_1945; Figure 2D). A SEFIR domain is usually found in IL17 receptors and SEF proteins, acting in eukaryotes signaling pathways. Very little is known about prokaryotic SEFIR-containing proteins. Structural analyses suggested that these bacterial SEFIR domains share structural and electrostatic similarity with their mammalian homologues and, thereby, could potentially subvert host immunity by hijacking the IL17R signaling pathways [63]. Notably, local production of IL-17 is a significant factor in effective host defense against Gram-negative bacteria, including K. pneumoniae [64]. Therefore, further studies are required to elucidate whether KpST66_1945 is implicated in K. pneumoniae pathogenesis.

\section{Distribution of Gls among K. pneumoniae strains}

To investigate the distribution of the described GIs in $K$. pneumoniae, the presence of the putative virulencerelated genes was searched using BlastN in 171 genomes, including 119 publicly available and 52 unpublished genomes (Bialek-Davenet, Brisse et al., unpublished work) representing 47 different sequence types (STs). Whereas the SEFIR-domain containing protein gene of GI-IV was only found in two (1.2\%) isolates of sequence type ST15, the three other GIs described herein were more distributed among K. pneumoniae isolates (Table 3). GI-II genes were present in a total of $11(6.4 \%)$ isolates, most of which belonged to ST375, ST65 and ST25, which were associated with severe infections caused by isolates of capsular serotype K2 $[9,65]$. The genes of GI-II were always found in synteny. GI-III genes were observed in only seven (4.1\%) isolates dispersed in several unrelated STs. The distribution of the ICEKpI element (similar to GI-I) has been previously analyzed [55].

\section{T6SS locus III insertion}

Recently, three different T6SS loci were defined in $K$. pneumoniae [38]. Within these loci, three putative valineglycine repeat (Vgr) proteins and two hemolysin-coregulated proteins (Hcp) were described as potential effector proteins, through their sequence similarities to Vibrio cholerae and Pseudomonas aeruginosa effector proteins [65-68]. Accordingly, the Kp52.145 genome also presented three conserved T6SS loci syntenic to those previously described. The first two loci were identical in composition and orientation to the previously described ones. The third one, locus III, had conservation of adjacency limited to the imcF/impG/impH and impJ/ompA/vgrG gene clusters, as a region with nine genes was inserted between these two clusters. This insertion encoded for one hypothetical protein, five putative Sel-1 repeat containing lipoproteins and three putative phospholipase $\mathrm{D}$ family proteins

Table 3 Prevalence of the genomic islands among K. pneumoniae isolates

\begin{tabular}{|c|c|c|c|}
\hline Genomic island & Virulence-related features & Prevalence (\%) & Remarkable STs \\
\hline \multirow[t]{2}{*}{$\overline{\mathrm{Gl}-\mathrm{I}}$} & Colibaction & $3.5^{\mathrm{a}}$ & - \\
\hline & Yersiniabactin & & \\
\hline \multirow[t]{2}{*}{ GI-II } & COMP & 5.8 & $3775,65,25$ \\
\hline & 4-phytase & & \\
\hline \multirow[t]{2}{*}{ GI-III } & lgg-like & 8.1 & Dispersed \\
\hline & Exonuclease & 57.6 & 375,65 \\
\hline GI-IV & Sefir-domain & 1.7 & - \\
\hline \multirow[t]{2}{*}{ T6SS insertion } & PLD1 & 7.0 & 380,35 \\
\hline & Sel 1 & 7.0 & 380,35 \\
\hline
\end{tabular}

according to ref. [55]. Prevalence of virulence-related features encoded in GI-II, GI-III, GI-IV and T6SS insertion was based on $>90 \%$ identity and $>50 \%$ coverage in the length of the genes, using a database of 171 Klebsiella genomes representative of 47 different STs. STs, sequence types. 
(Figure 1A). Flanking sequences suggesting how this region was inserted were not found.

Sel1 lipoproteins are poorly characterized and there was no evidence for their function in $K$. pneumoniae, but they are essential in Legionella pneumophila for invasion of host cells where they influence vacuolar trafficking of bacteria [69]. The three open reading frames encoding putative phospholipase D proteins in strain Kp52.145 encoded one full length protein (KpST66_3368, 623 aminoacids), one C-terminal region (KpST66_3371, 187 aa) and one N-terminal region (KpST66_3372, 317 aa). Phospholipase $\mathrm{D}$ family proteins have been described as important for host cell invasion, bacterial dissemination and disease progression [70-73]. The bacterial phospholipase D family comprises at least four classes of proteins with distinct functions: true phospholipase D, cardiolipin synthase, phosphatidylserine synthase and endonuclease [74]. Full length $K$. pneumoniae PLD1 and its closest homologs all presented the conserved motif $\operatorname{HXK}(X)_{4} \mathrm{D}$ and a serine or threonine approximately eight residues after asparagine (Figure 3), but no other conserved domain was described in each family, thus making it difficult to infer protein function only by sequence analysis.

In order to obtain evidence that the product of these three genes coding either for full length or partial PLD-family proteins are important for bacterial survival in vivo, we checked by RT-PCR for their mRNA expression. We observed that these genes are expressed both in bacteria grown for four hours in Trypto Casein Soy broth (GTCS) medium, as well as in the lungs of mice infected for 24 hours (data not shown). These results prompted us to further check for a putative involvement of the full length PLD gene, called pld1, on K. pneumoniae virulence.

\section{Involvement of the phospholipase D family protein gene pld1 in KP 52.145 virulence}

As PLD-family proteins have been shown to be involved in virulence [75-77], we decided to characterize the role of the full length PLD1 protein. We first tested a pld mutant strain in a $K$. pneumoniae murine model. Mice were infected intranasally with $10^{8}$ of either the wild-type bacteria, a pld1 mutant, or the mutant strain complemented with a plasmid expressing the putative PLD1 protein (pPLD), and their survival was monitored for seven days. Interestingly, the mutant strain appeared avirulent in a mouse model of acute pneumonia while mice infected with the wild-type and the complemented strain succumbed in less than one week (Figure 4). However, the wild-type, the mutant and the complemented mutant strains grew equally well in Luria-Bertani broth (LB) broth (data not shown). These results indicated that the pld 1 mutant was strongly attenuated in vivo, thus showing an important role for PLD1 in virulence.
To analyze the frequency and clonal distribution of the pld1 gene in K. pneumoniae, the 171 genomes were analyzed using BlastN. We observed that besides ST66, represented by strain Kp52.145, pld1 was present in 10 strains (6.4\%) belonging to ST380, ST679, ST67 (K. pneumoniae subsp. rhinoscleromatis) and ST35, but in none of the other isolates. It is interesting to note that ST380 was associated with severe $K$. pneumoniae infections $[9,65]$ and that $K$. pneumoniae subsp. rhinoscleromatis is the only Klebsiella strain to be able to survive intracellularly in macrophages [78].

\section{Functional characterization of PLD1}

In order to demonstrate the phospholipase activity of PLD1 and characterize its involvement in lipid metabolism, the lipid composition of wild-type and mutant strains was analyzed by thin-layer chromatography (TLC). A remarkable lipid spot was absent from the pld 1 mutant in comparison with the complemented strain, suggesting that the putative PLD1 is involved in lipid metabolism [see Additional file 1]. To reinforce this result, a plasmid carrying the pld1 gene was inserted into E. coli strain SD9 [79]. This strain is deficient in phosphatidylserine and cardiolipin, thus presenting a simpler lipid composition than its parental strain and Kp52.145. Lipid profiles of SD9 and complemented strains had a different lipid composition. Notably, the PLD1-expressing strain contained an additional lipid spot in comparison to the SD9 strain, suggesting that PLD1 is responsible for this difference (Figure 5A). SD9 wild-type strain also presented an extra lipid spot in comparison to the PLD1-expressing strain, possibly representing the PLD1 substrate (Figure 5A). Densitometric analysis of iodine-stained lipids on TLC plates revealed that this lipid spot corresponded to $21 \%$ of the total amount of lipids in SD9 strain, but only 6\% of SD9 complemented with a plasmid expressing pld1. Mass spectrometry (MS) analysis of total lipid extract was carried out to identify such lipid. Comparing lipid profiles by MS, we found a lipid of mass 788.4 present only in the PLD1-deficient strain (Figure 5B) and identified it as phosphatidyl glycerol (PG) using the LipidMaps database.

As mentioned above, the bacterial PLD-family proteins can be classified in four subfamilies. One of them, the cardiolipin synthase is able to convert two PG molecules into glycerol and cardiolipin, or to catalyze the opposite reaction, leading to $\mathrm{PG}$ formation [80]. Our results suggest that PLD1 belongs to the cardiolipin synthase subfamily and that it plays a role in balancing the PG and cardiolipin content.

It has been shown that humans and mice with bacterial pneumonia have markedly elevated amounts of cardiolipin in lung fluid and that it impairs surfactant function, lung mechanics, modulation of cell survival and cytokine networks and lung consolidation [81]. 


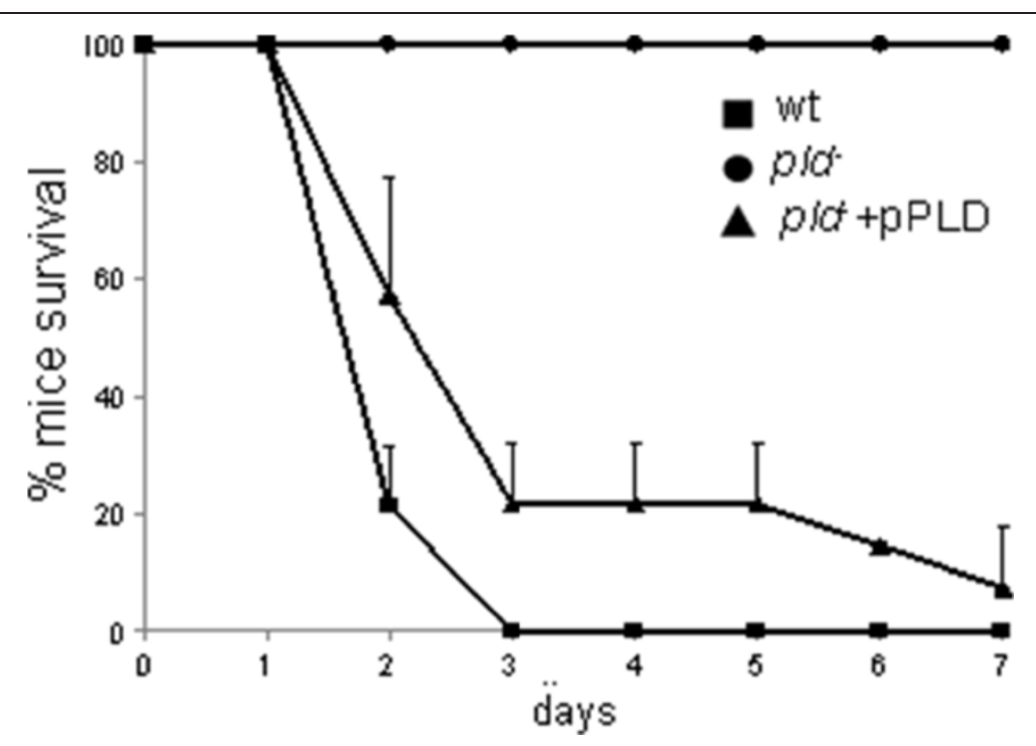

Figure 4 PLD1 involvement in K. pneumoniae virulence. Mice survival after infection with K. pneumoniae Kp52.145 wild-type, pld1 mutant and complemented strains. Data are representative of seven mice per group from two independent experiments. Standard deviation is shown. PLD, phospholipase D.

There is evidence that bacteria are able to adjust their relative concentrations of phosphatidylethanolamine and PGs when subjected to environmental stresses. Such an alteration in headgroup composition seems to be a means for changing membrane permeability and, hence, preserving stability [82]. Therefore, we hypothesize that PLD1 alters the membrane composition and charge, affecting bacterial interaction with the host environment.

Recently, Russel el. al. demonstrated that diverse phospholipase proteins encoded within the T6SS loci of several prokaryotic genomes are antibacterial effectors, conferring competitive advantages on the donor strain during interbacterial interactions [83]. These proteins are generally designated as 'T6SS Lipase Effectors' (Tle) and classified in five sub-families, according to the sequence conservation and number of catalytic motifs present. Kp52.145 PLD-family protein could be considered a Tle 5 member, as it presents two conserved HxKxxxxD motifs. However, in the Kp52.145 genome we did not identify any gene similar to the cognate immunity genes - a hallmark of the genomic islands described by Russel et al. Moreover, we did not observe such an antibacterial effect of Kp52.145 or its PLD1 mutant strain upon competition with $E$. coli [see Additional file 1]. These results showed that pld1 is implicated in virulence without being an anti-bacterial factor and is, so far, unique.

\section{Conclusions}

This study presents a comparative analysis of the complete genome sequence of the high virulence reference strain Kp52.145, a derivative of the K2 reference strain B5055. It revealed five genomic regions possibly involved in bacterial virulence. One gene, pld1, was shown to be involved in virulence in a mouse model of pneumonia and revealed a novel implication of lipid metabolism in $K$. pneumoniae pathogenesis. Future analysis of additional putative virulence factors such as Sel1 lipoproteins, VgrG, Hcp, Bcl, cOMP and Sefir-domain containing protein are required for a comprehensive understanding of $K$. pneumoniae core virulence genes.

\section{Methods}

Selection of isolates for genome sequencing/bacterial strains

Strain Kp25.145 (a derivative of B5055, the reference strain of serotype K2) is a laboratory strain used to study K. pneumoniae pathogenesis $[11,21]$ and was chosen as the focus of this work. SB2390 (cur15505, isolated in Curaçao, 2002, urinary tract infection; belongs to ST14) and SB3193 (IPEUC-744, isolated from a metritis case in a mare, 1981 in France; belonging to ST82) [23] are non-virulent strains that were sequenced to allow the comparison between virulent and non-virulent strains.

The pld 1 transposon mutant was isolated by Anna Tomas and Jose Bengoecheoa during a screen of a $K$. pneumoniae mutant library made by $\operatorname{Tn} 5$ transposon insertion (manuscript in preparation). In this mutant, the transposon was inserted at position 1,625 of pld 1 gene.

The complementation of the mutant strain was achieved through bacterial transformation using electrocompetent cells and a plasmid carrying pld 1 gene. pld 1 gene was amplified by PCR and cloned at the multiple 

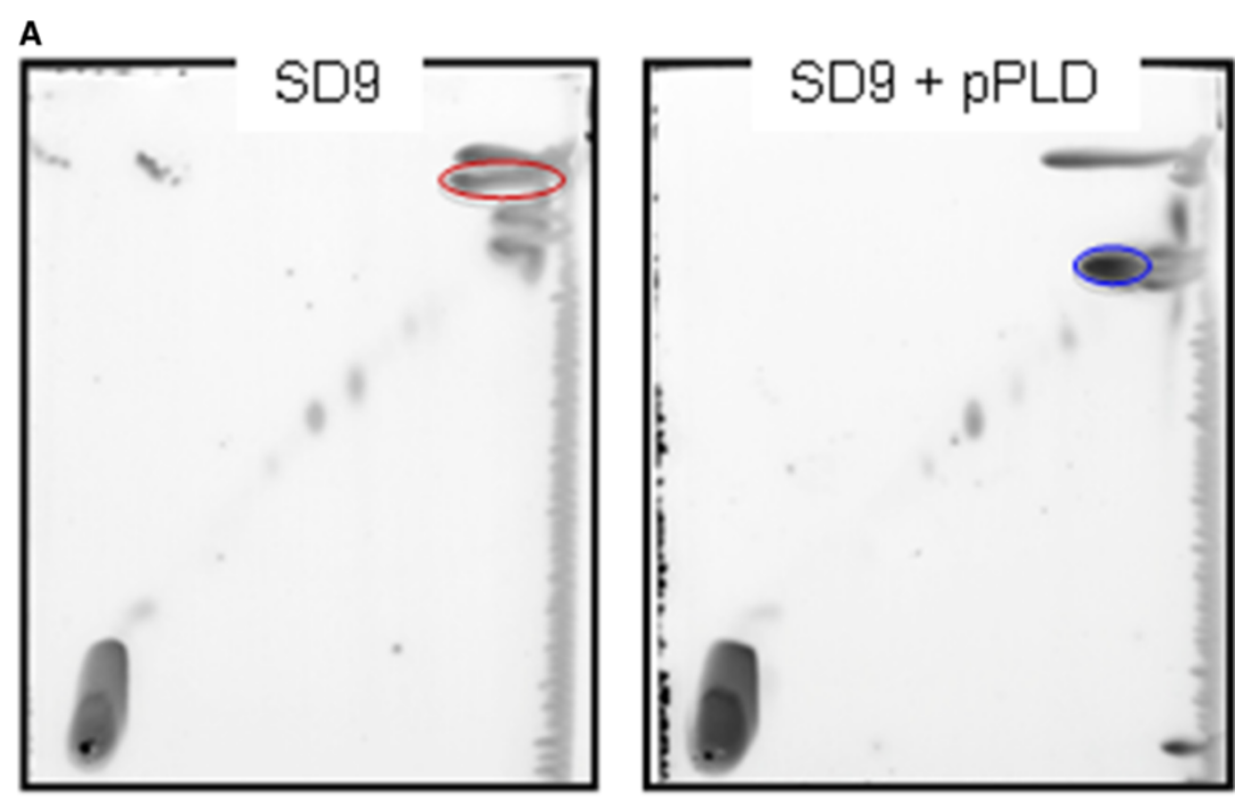

B
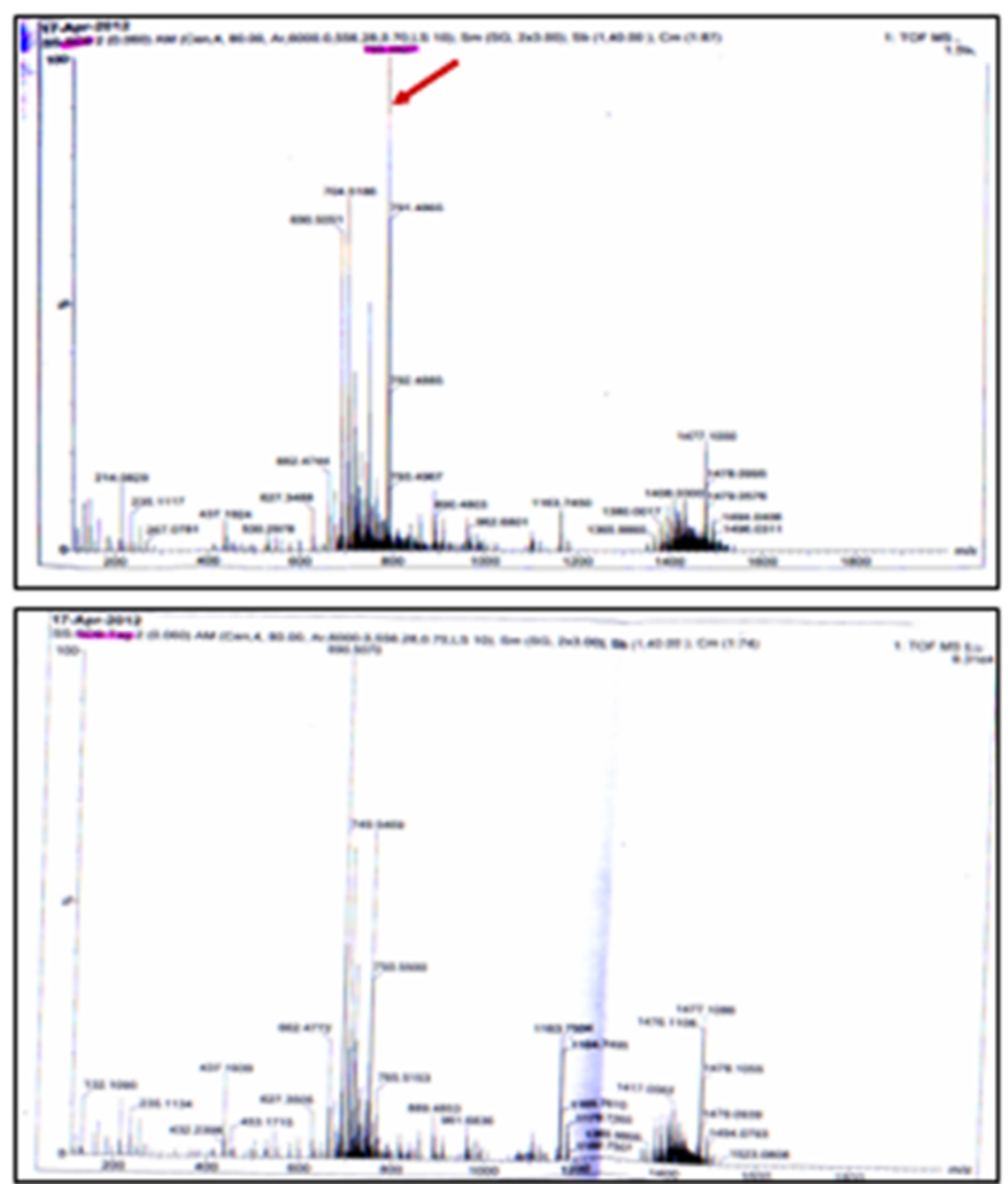

Figure $\mathbf{5}$ (See legend on next page.) 
cloning site of puc18 plasmid. Cloning was confirmed by DNA sequencing.

\section{Genome sequencing and assembly}

$K$. pneumoniae strains were sequenced using a combination of 454 and Illumina reads. Single and paired-end 454 reads with an average of 400 nucleotides were assembled into contigs and scaffolds by Newbler. Illumina reads of about 76 or 36 nucleotides were aligned to scaffolds in order to confirm and correct possible homopolymer errors in the 454 reads. Coverage was as follows: Kp52.145 genome: $170 \mathrm{X}$ using GAIIX (76 nt) $+13.8 \mathrm{X}$ using MP titanium $+18 \mathrm{X}$ using SR titanium; SB2390 genome: $81 \mathrm{X}$ using GAIIX (36 nt) $+6.4 \mathrm{X}$ using MP titanium $+22 X$ using SR titanium; SB3193 genome: $209 \mathrm{X}$ using GAIIX (76 nt) $+5.4 \mathrm{X}$ using MP titanium $+20 \mathrm{X}$ using SR titanium.

Following the primary assembly of the genomes, an in silico finishing approach, based on the methods described by Pop et al. [84], was performed in order to identify small and identical repeats on the genomes. In such cases and without high quality bases discrepancies, the contigs containing the small repeats were manually duplicated and added to the assembly.

Scaffolds were aligned to experimentally determined BglII optical maps generated by OpGen company from purified chromosomal DNA, using MapSolver version 3.1 software. Such alignments were used to check for the quality of the assemblies. Additionally, specific pairs of primers were designed in order to close all remaining gaps. PCR products were purified in NucleoFast 96 plates (Macherey Nagel, Düren, Germany) and aliquots were used for sequencing reactions with the BigDye Terminator Cycle Sequencing Ready reaction Kit (Applied Biosystems, Foster City, CA, USA) on a ABI Prism 3730XL DNA Analyzer (Applied Biosystems). The resulting sequences were added to the previous assembly using Phred/Phrap/Consed.

The sequences of K. pneumoniae genomes have been deposited to the European Nucleotide Archive and are accessible under the accession numbers: FO834904, FO834905 and FO834906 (strain Kp52.145), CCBO00000000 (strain SB2390) and CCCQ000000000 (strain SB3193).

\section{Functional annotation of genomes}

In order to gain functional insights about the genome sequences, protein-coding genes were predicted and annotated using the CAAT-box genome browser [85], using a combination of GeneMark predictions and Blastx results against the Uniprot database. All the putative open reading frames (ORF) longer than 120 nucleotides presenting similarity to sequences of the Uniprot database or positive GeneMark result were considered for further analysis. The final set of CDSs underwent a manual annotation process based on description of similarity. Pfam and COG database searches, as well as SignalP, TMHMM and PredTMBB predictions were performed to improve the degree of annotation confidence, if necessary. CDSs were described as 'highly similar to', 'similar to' or 'weakly similar to' if they presented more than $70 \%$, between $50 \%$ and $69 \%$ or less than $50 \%$ similarity to the protein hit sequence. Additionally, information on partial homology was included. The start codon for each CDS was automatically chosen and manually validated, based on a combination of GeneMark results and Blast alignments. RAST was used to classify proteins in functional categories. Structural RNAs were searched using tRNAscan.

The common genome of the five strains was determined using the BlastClust algorithm [86] using minimum parameters of $90 \%$ identity and $80 \%$ length coverage for proteins to be included in the same cluster.

\section{RT-PCR}

Lungs of control or Kp52.145-infected mice were homogenized in cold TRI reagent (Sigma, Gillingham, Dorset, UK) using a Precellys lysing kit (Precellys, Saint Quentin en Yvelines, France). Total lung and bacterial mRNAs were extracted according to the manufacturer's instructions. RNA $(2 \mu \mathrm{g})$ was reversed transcribed in cDNA using Superscript II enzyme (Invitrogen, Foster City, CA, USA). Aliquots were used in PCR reactions using specific primers [see Additional file 1].

\section{Animal experiments}

$\mathrm{BALB} / \mathrm{cJ}$ mice were purchased from Janvier (Le Genest St. Isle, France). Mice were housed under standard conditions of feeding, light and temperature with access to food and water ad libidium. Experiments were performed according to the national and Institut Pasteur guidelines for laboratory animal experiments. Protocols were approved by the Institut Pasteur animal care and use committee (protocol 05-59) and the Direction des Services Vétérinaire de Paris (permit 75-713 to RT). Six- to eight-week-old mice were anesthetized with acepromazine (Calmivet, $1.5 \mathrm{mg} / \mathrm{kg}$, Vetoquinol, Lure, France). and ketamine (Imalgene, $31.25 \mathrm{mg} / \mathrm{kg}$, Merial, Lyon, France). and then infected intranasally with $20 \mu \mathrm{l}$ 
bacterial suspension. The virulence of $K$. pneumoniae strains was tested on six-week-old BALB/c mice, as previously described [23]. Seven mice per test condition were infected with $10^{8}$ bacteria. Mice were followed every day for one week. Experiments were performed at least twice.

\section{Thin-layer chromatography and mass spectrometry of lipids}

Bacterial lipids were extracted by the method of Bligh and Dyer [87]. Briefly, bacterial stationary-phase cultures were concentrated 10 times and mixed with chloroform: methanol. After centrifugation at 1,000 rpm for five minutes, the organic phase was recovered. Lipid profiles were analyzed by two-dimensional TLC using TLC Silica gel $60 \mathrm{~F}_{254}$ plates (Merck, Whitehouse Station, NJ, USA). as the stationary phase and a chloroform 9:1 methanol mixture as the mobile phase in both dimensions. Staining was performed by iodine vapor. TLC calibrated images were aquired in ImageScanner using LabScan v5.0 software. The relative intensity of each spot was calculated in ImageMaster two-dimensional Platinum v7.0 software. Alternatively, lipid extracts were analyzed by MS and MS/MS in an ESI-Q-Tof Micro (Waters), in positive ion mode. Resolution was typically lower than $10 \mathrm{ppm}$.

\section{Anti-bacterial competition assays}

Competition assays were performed as previously described [88]. Briefly, K. pneumoniae Kp52.145 or its pld1 mutant cells grown overnight on an agar plate were resuspended in $\mathrm{LB}$, normalized to $\mathrm{OD}_{600}$ of 0.5 and mixed at a ratio of 5:1 with a spontaneous nalidixic acid (nal) resistant mutant strain of $E$. coli MG1655. The mixture was incubated for four hours on a prewarmed agar plate. Recovered cells were plated out on antibiotic selective media and viable cells were reported as the total number recovered per co-culture spot. Serratia marcescens DB10 was used as a positive control.

\section{Additional file}

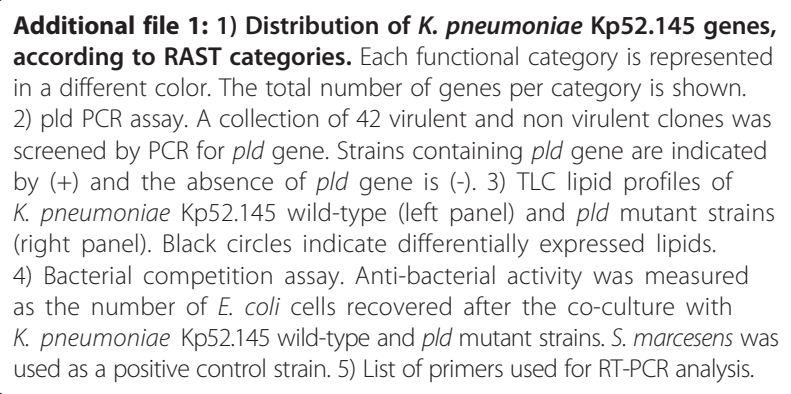

\section{Competing interests}

The authors declare they have no competing interests.

\section{Authors' contributions}

LMSL participated in the genome sequencing and assembly, carried out the annotation and comparative genomic analysis, performed RT-PCR, lipid analysis and animal experiments and drafted the manuscript. LF carried out the genome assembly and participated in genome annotation. AT and JB generated the mutant strain and carried out the bacterial competition assay. VP, ASA and VB participated in the genome sequencing. SB participated in the design of the study and the genome sequencing and assembly. PS participated in the study design and coordination. RT conceived the study, participated in the genome sequencing and assembly and carried out animal experiments. SBD analyzed the presence of genes within other K. pneumoniae genomes. LMLS, JB, PJS, SB and RT wrote the manuscript. All authors read and approved the final manuscript.

\section{Acknowledgements}

LMSL, AT and this work were supported by an ERA-Net Pathogenomic 2008 grant allocated to both P. Sansonetti and J. Bengoechea. ASA is a recipient of a fellowship from the Fundação para a Ciência e a Tecnologia from Portugal. The authors thank Stephane Salamone and David Touboul for their help with lipid analysis.

\section{Author details}

${ }^{1}$ Institut Pasteur - Pathogénie Microbienne Moléculaire, Paris, France. ${ }^{2}$ INSERM U786, Paris, France. ${ }^{3}$ Institut Pasteur - Genome Bioinformatics Platform, Paris, France. ${ }^{4}$ Laboratory Microbial Pathogenesis, Fundació d'Investigació Sanitària de les Illes Balears (FISIB), Bunyola, Spain. ${ }^{5}$ Program Host-Pathogen Interactions, Centro de Investigación Biomédica en Red Enfermedades Respiratorias (CibeRes), Bunyola, Spain. Institut Pasteur Microbial Evolutionary Genomics, Paris, France. ${ }^{7}$ CNRS, UMR3525, Paris, France. ${ }^{8} \mathrm{CEA} / \mathrm{IG} /$ Genoscope, Finishing Laboratory, Evry, France. ${ }^{9}$ Microbiologie et Maladies Infectieuses, Collège de France, Paris, France. ${ }^{10}$ Present address: Biological Physics Laboratory, Institute of Biophysics Carlos Chagas Filho at the Federal University of Rio de Janeiro, Av. Carlos Chagas Filho, 373, Prédio do CCS, Bloco G, Sala G1-043, Rio de Janeiro, RJ 21941-902, Brazil. " Present address: Cold Spring Harbor Laboratory, Bungtown Road, Cold Spring Harbor, NY 11724, USA. ${ }^{12}$ Present address: Centre for Infection and Immunity, Queen's University Belfast, Belfast, UK. ${ }^{13}$ Present address: Plate-Forme d'Imagerie Dynamique, Imagopole, Institut Pasteur, 28 rue du Docteur Roux, 75724 Paris, Cedex 15, France.

Received: 14 May 2014 Accepted: 15 May 2014

Published: 29 May 2014

\section{References}

1. Brisse S, Grimont F, Grimont PAD: The genus Klebsiella. In The Prokaryotes: A Handbook on the Biology of Bacteria, Volume 6. 3rd edition. New York: Springer NY; 2006:159-196.

2. Keynan $Y$, Rubinstein $E$ : The changing face of Klebsiella pneumoniae infections in the community. Int J Antimicrob Agents 2007, 30:385-389.

3. Podschun R, Ullmann U: Klebsiella spp. as nosocomial pathogens: epidemiology, taxonomy, typing methods, and pathogenicity factors. Clin Microbiol Rev 1998, 11:589-603.

4. Moellering RC Jr: NDM-1-a cause for worldwide concern. N Engl J Med 2010, 363:2377-2379.

5. Shon AS, Russo TA: Hypervirulent Klebsiella pneumoniae: the next superbug? Future Microbiol 2012, 7:669-671.

6. Su SC, Siu LK, Ma L, Yeh KM, Fung CP, Lin JC, Chang FY: Community-acquired liver abscess caused by serotype K1 Klebsiella pneumoniae with CTX-M-15type extended-spectrum beta-lactamase. Antimicrob Agents Chemother 2008, 52:804-805.

7. Siu LK, Yeh KM, Lin JC, Fung CP, Chang FY: Klebsiella pneumoniae liver abscess: a new invasive syndrome. Lancet Infect Dis 2012, 12:881-887.

8. Yoon JH, Kim YJ, Jun YH, Kim SI, Kang JY, Suk KT, Kim DJ: Liver abscess due to Klebsiella pneumoniae: Risk factors for metastatic infection. Scand J Infect Dis 2014, 46:21-26.

9. Decre D, Verdet C, Emirian A, Le Gourrierec T, Petit JC, Offenstadt G, Maury E, Brisse S, Arlet G: Emerging severe and fatal infections due to Klebsiella pneumoniae in two university hospitals in France. J Clin Microbiol 2011, 49:3012-3014.

10. Nassif $X$, Honore N, Vasselon T, Cole ST, Sansonetti PJ: Positive control of colanic acid synthesis in Escherichia coli by rmpA and rmpB, two 
virulence-plasmid genes of Klebsiella pneumoniae. Mol Microbio/ 1989, 3:1349-1359.

11. Nassif X, Fournier JM, Arondel J, Sansonetti PJ: Mucoid phenotype of Klebsiella pneumoniae is a plasmid-encoded virulence factor. Infect Immun 1989, 57:546-552.

12. Regue M, Hita B, Pique N, Izquierdo L, Merino S, Fresno S, Benedi VJ, Tomas JM: A gene, uge, is essential for Klebsiella pneumoniae virulence. Infect Immun 2004, 72:54-61.

13. Mey A, Ponard D, Colomb M, Normier G, Binz H, Revillard JP: Acylation of the lipid A region of a Klebsiella pneumoniae LPS controls the alternative pathway activation of human complement. Mol Immunol 1994, 31:1239-1246.

14. Izquierdo L, Coderch N, Pique N, Bedini E, Corsaro MM, Merino S, Fresno S, Tomas JM, Regue M: The Klebsiella pneumoniae wabG gene: role in biosynthesis of the core lipopolysaccharide and virulence. J Bacteriol 2003, 185:7213-7221.

15. Llobet E, Tomas JM, Bengoechea JA: Capsule polysaccharide is a bacterial decoy for antimicrobial peptides. Microbiology 2008, 154:3877-3886.

16. Campos MA, Vargas MA, Regueiro V, Llompart CM, Alberti S, Bengoechea JA: Capsule polysaccharide mediates bacterial resistance to antimicrobial peptides. Infect Immun 2004, 72:7107-7114.

17. Moranta D, Regueiro V, March C, Llobet E, Margareto J, Larrarte E, Garmendia J, Bengoechea JA: Klebsiella pneumoniae capsule polysaccharide impedes the expression of beta-defensins by airway epithelial cells. Infect Immun 2010, 78:1135-1146.

18. Yeh KM, Kurup A, Siu LK, Koh YL, Fung CP, Lin JC, Chen TL, Chang FY, Koh $\mathrm{TH}$ : Capsular serotype $\mathrm{K} 1$ or $\mathrm{K} 2$, rather than magA and $\mathrm{rmpA}$, is a major virulence determinant for Klebsiella pneumoniae liver abscess in Singapore and Taiwan. J Clin Microbiol 2007, 45:466-471.

19. Mizuta K, Ohta M, Mori M, Hasegawa T, Nakashima I, Kato N: Virulence for mice of Klebsiella strains belonging to the 01 group: relationship to their capsular (K) types. Infect Immun 1983, 40:56-61.

20. Simoons-Smit AM, Verwey-van Vught AM, Kanis IY, MacLaren DM: Virulence of Klebsiella strains in experimentally induced skin lesions in the mouse. J Med Microbiol 1984, 17:67-77.

21. Nassif $X$, Sansonetti PJ: Correlation of the virulence of Klebsiella pneumoniae $\mathrm{K} 1$ and $\mathrm{K} 2$ with the presence of a plasmid encoding aerobactin. Infect Immun 1986, 54:603-608.

22. Fung CP, Chang FY, Lee SC, Hu BS, Kuo Bl, Liu CY, Ho M, Siu LK: A global emerging disease of Klebsiella pneumoniae liver abscess: is serotype K1 an important factor for complicated endophthalmitis? Gut 2002, 50:420-424.

23. Brisse S, Fevre C, Passet V, Issenhuth-Jeanjean S, Tournebize R, Diancourt L, Grimont P: Virulent clones of Klebsiella pneumoniae: identification and evolutionary scenario based on genomic and phenotypic characterization. PLoS One 2009, 4:e4982.

24. Wu KM, Li LH, Yan JJ, Tsao N, Liao TL, Tsai HC, Fung CP, Chen HJ, Liu YM, Wang JT, Fang CT, Chang SC, Shu HY, Liu TT, Chen YT, Shiau YR, Lauderdale TL, Su IJ, Kirby R, Tsai SF: Genome sequencing and comparative analysis of Klebsiella pneumoniae NTUH-K2044, a strain causing liver abscess and meningitis. J Bacterio/ 2009, 191:4492-4501.

25. Aziz RK, Bartels D, Best AA, DeJongh M, Disz T, Edwards RA, Formsma K, Gerdes S, Glass EM, Kubal M, Meyer F, Olsen GJ, Olson R, Osterman AL, Overbeek RA, McNeil LK, Paarmann D, Paczian T, Parrello B, Pusch GD, Reich C, Stevens R, Vassieva O, Vonstein V, Wilke A, Zagnitko O: The RAST Server: rapid annotations using subsystems technology. BMC Genomics 2008, 9:75.

26. Di Martino P, Cafferini N, Joly B, Darfeuille-Michaud A: Klebsiella pneumoniae type 3 pili facilitate adherence and biofilm formation on abiotic surfaces. Res Microbiol 2003, 154:9-16.

27. Lavender HF, Jagnow JR, Clegg S: Biofilm formation in vitro and virulence in vivo of mutants of Klebsiella pneumoniae. Infect Immun 2004, 72:4888-4890.

28. Balestrino D, Haagensen JA, Rich C, Forestier C: Characterization of type 2 quorum sensing in Klebsiella pneumoniae and relationship with biofilm formation. J Bacteriol 2005, 187:2870-2880.

29. Agladze K, Wang X, Romeo T: Spatial periodicity of Escherichia coli K-12 biofilm microstructure initiates during a reversible, polar attachment phase of development and requires the polysaccharide adhesin PGA. J Bacteriol 2005, 187:8237-8246.

30. Torres AG, Jeter C, Langley W, Matthysse AG: Differential binding of Escherichia coli 0157:H7 to alfalfa, human epithelial cells, and plastic is mediated by a variety of surface structures. Appl Environ Microbio/ 2005, 71:8008-8015.

31. Teplitski M, Al-Agely A, Ahmer BM: Contribution of the SirA regulon to biofilm formation in Salmonella enterica serovar Typhimurium. Microbiology 2006, 152:3411-3424.

32. Suzuki K, Wang X, Weilbacher T, Pernestig AK, Melefors O, Georgellis D, Babitzke P, Romeo T: Regulatory circuitry of the CsrA/CsrB and BarA/UvrY systems of Escherichia coli. J Bacterio/ 2002, 184:5130-5140.

33. Khan MA, Isaacson RE: Identification of Escherichia coli genes that are specifically expressed in a murine model of septicemic infection. Infect Immun 2002, 70:3404-3412.

34. Baldi DL, Higginson EE, Hocking DM, Praszkier J, Cavaliere R, James CE, Bennett-Wood V, Azzopardi Kl, Turnbull L, Lithgow T, Robins-Browne RM, Whitchurch CB, Tauschek M: The Type II secretion system and its ubiquitous lipoprotein substrate, $\mathrm{SsIE}$, are required for biofilm formation and virulence of enteropathogenic Escherichia coli. Infect Immun 2012, 80:2042-2052

35. Iwobi A, Heesemann J, Garcia E, Igwe E, Noelting C, Rakin A: Novel virulence-associated type II secretion system unique to high-pathogenicity Yersinia enterocolitica. Infect Immun 2003, 71:1872-1879.

36. Hytonen J, Haataja S, Finne J: Streptococcus pyogenes glycoprotein-binding strepadhesin activity is mediated by a surface-associated carbohydratedegrading enzyme, pullulanase. Infect Immun 2003, 71:784-793.

37. Shelburne SA 3rd, Keith DB, Davenport MT, Beres SB, Carroll RK, Musser JM: Contribution of AmyA, an extracellular alpha-glucan degrading enzyme, to group A streptococcal host-pathogen interaction. Mol Microbiol 2009, 74:159-174.

38. Sarris PF, Zoumadakis C, Panopoulos NJ, Scoulica EV: Distribution of the putative type VI secretion system core genes in Klebsiella spp. Infect Genet Evol 2011, 11:157-166.

39. Lawlor MS, Hsu J, Rick PD, Miller VL: Identification of Klebsiella pneumoniae virulence determinants using an intranasal infection model. Mol Microbiol 2005, 58:1054-1073.

40. Ge Z, Feng Y, Dangler CA, Xu S, Taylor NS, Fox JG: Fumarate reductase is essential for Helicobacter pylori colonization of the mouse stomach. Microb Pathog 2000, 29:279-287.

41. Li AH, Lam WL, Stokes RW: Characterization of genes differentially expressed within macrophages by virulent and attenuated Mycobacterium tuberculosis identifies candidate genes involved in intracellular growth. Microbiology 2008, 154:2291-2303.

42. Buettner FF, Bendallah IM, Bosse JT, Dreckmann K, Nash JH, Langford PR, Gerlach GF: Analysis of the Actinobacillus pleuropneumoniae ArcA regulon identifies fumarate reductase as a determinant of virulence. Infect Immun 2008, 76:2284-2295.

43. Mercado-Lubo R, Gauger EJ, Leatham MP, Conway T, Cohen PS: A Salmonella enterica serovar typhimurium succinate dehydrogenase/ fumarate reductase double mutant is avirulent and immunogenic in BALB/c mice. Infect Immun 2008, 76:1128-1134.

44. Wu MC, Lin TL, Hsieh PF, Yang HC, Wang JT: Isolation of genes involved in biofilm formation of a Klebsiella pneumoniae strain causing pyogenic liver abscess. PLoS One 2011, 6:e23500.

45. Flower DR: The lipocalin protein family: structure and function. Biochem J 1996, 318:1-14.

46. Bachman MA, Lenio S, Schmidt L, Oyler JE, Weiser JN: Interaction of lipocalin 2, transferrin, and siderophores determines the replicative niche of Klebsiella pneumoniae during pneumonia. MBio 2012, 3:6.

47. Warszawska JM, Gawish R, Sharif O, Sigel S, Doninger B, Lakovits K, Mesteri I, Nairz M, Boon L, Spiel A, Fuhrmann V, Strobl B, Muller M, Schenk P, Weiss G, Knapp S: Lipocalin 2 deactivates macrophages and worsens pneumococcal pneumonia outcomes. J Clin Invest 2013, 123:3363-3372.

48. Chen YL, Montedonico AE, Kauffman S, Dunlap JR, Menn FM, Reynolds TB: Phosphatidylserine synthase and phosphatidylserine decarboxylase are essential for cell wall integrity and virulence in Candida albicans. Mol Microbiol 2010, 75:1112-1132.

49. Conde-Alvarez R, Grillo MJ, Salcedo SP, de Miguel MJ, Fugier E, Gorvel JP, Moriyon I, Iriarte M: Synthesis of phosphatidylcholine, a typical eukaryotic phospholipid, is necessary for full virulence of the intracellular bacterial parasite Brucella abortus. Cell Microbio/ 2006, 8:1322-1335.

50. Tang HL, Chiang MK, Liou WJ, Chen YT, Peng HL, Chiou CS, Liu KS, Lu MC, Tung KC, Lai YC: Correlation between Klebsiella pneumoniae carrying 
pLVPK-derived loci and abscess formation. Eur J Clin Microbiol Infect Dis 2010, 29:689-698.

51. Wacharotayankun R, Arakawa Y, Ohta M, Tanaka K, Akashi T, Mori M, Kato N: Enhancement of extracapsular polysaccharide synthesis in Klebsiella pneumoniae by RmpA2, which shows homology to NtrC and FixJ. Infect Immun 1993, 61:3164-3174.

52. Hsu CR, Lin TL, Chen YC, Chou HC, Wang JT: The role of Klebsiella pneumoniae rmpA in capsular polysaccharide synthesis and virulence revisited. Microbiology 2011, 157:3446-3457.

53. Hochhut B, Dobrindt $U$, Hacker J: Pathogenicity islands and their role in bacterial virulence and survival. Contrib Microbiol 2005, 12:234-254.

54. Gal-Mor O, Finlay BB: Pathogenicity islands: a molecular toolbox for bacterial virulence. Cell Microbiol 2006, 8:1707-1719.

55. Putze J, Hennequin C, Nougayrede JP, Zhang W, Homburg S, Karch $H$, Bringer MA, Fayolle C, Carniel E, Rabsch W, Oelschlaeger TA, Oswald E, Forestier C, Hacker J, Dobrindt U: Genetic structure and distribution of the colibactin genomic island among members of the family Enterobacteriaceae. Infect Immun 2009, 77:4696-4703.

56. Lin TL, Lee CZ, Hsieh PF, Tsai SF, Wang JT: Characterization of integrative and conjugative element ICEKp1-associated genomic heterogeneity in a Klebsiella pneumoniae strain isolated from a primary liver abscess. J Bacteriol 2008, 190:515-526

57. Tsugawa H, Ogawa A, Takehara S, Kimura M, Okawa Y: Primary structure and function of a cytotoxic outer-membrane protein (ComP) of Plesiomonas shigelloides. FEMS Microbiol Lett 2008, 281:10-16.

58. Shah P, Nanduri B, Swiatlo E, Ma Y, Pendarvis K: Polyamine biosynthesis and transport mechanisms are crucial for fitness and pathogenesis of Streptococcus pneumoniae. Microbiology 2011, 157:504-515.

59. Wortham BW, Oliveira MA, Fetherston JD, Perry RD: Polyamines are required for the expression of key Hms proteins important for Yersinia pestis biofilm formation. Environ Microbiol 2010, 12:2034-2047.

60. Choy HA, Kelley MM, Chen TL, Moller AK, Matsunaga J, Haake DA: Physiological osmotic induction of Leptospira interrogans adhesion: LigA and LigB bind extracellular matrix proteins and fibrinogen. Infect Immun 2007, 75:2441-2450.

61. Castiblanco-Valencia MM, Fraga TR, Silva LB, Monaris D, Abreu PA, Strobel S, Jozsi M, Isaac L, Barbosa AS: Leptospiral immunoglobulin-like proteins interact with human complement regulators factor $\mathrm{H}, \mathrm{FHL}-1, \mathrm{FHR}-1$, and C4BP. J Infect Dis 2012, 205:995-1004.

62. Beiter K, Wartha F, Albiger B, Normark S, Zychlinsky A, Henriques-Normark B: An endonuclease allows Streptococcus pneumoniae to escape from neutrophil extracellular traps. Curr Biol 2006, 16:401-407.

63. Wu B, Gong J, Liu L, Li T, Wei T, Bai Z: Evolution of prokaryotic homologues of the eukaryotic SEFIR protein domain. Gene 2012,492:160-166.

64. Ye P, Garvey PB, Zhang P, Nelson S, Bagby G, Summer WR, Schwarzenberger $P$, Shellito JE, Kolls JK: Interleukin-17 and lung host defense against Klebsiella pneumoniae infection. Am J Respir Cell Mol Biol 2001, 25:335-340.

65. Bialek-Davenet S, Nicolas-Chanoine MH, Decre D, Brisse S: Microbiological and clinical characteristics of bacteraemia caused by the hypermucoviscosity phenotype of Klebsiella pneumoniae in Korea. Epidemiol Infect 2013 2:141-188.

66. Miyata ST, Kitaoka M, Wieteska L, Frech C, Chen N, Pukatzki S: The Vibrio cholerae Type VI secretion system: evaluating its role in the human disease cholera. Front Microbiol 2010, 1:117.

67. Shrivastava S, Mande SS: Identification and functional characterization of gene components of Type VI secretion system in bacterial genomes. PLoS One 2008, 3:e2955.

68. Boyer F, Fichant G, Berthod J, Vandenbrouck Y, Attree I: Dissecting the bacterial type VI secretion system by a genome wide in silico analysis: what can be learned from available microbial genomic resources? BMC Genomics 2009, 10:104.

69. Newton HJ, Sansom FM, Dao J, McAlister AD, Sloan J, Cianciotto NP, Hartland EL: Sel1 repeat protein LpnE is a Legionella pneumophila virulence determinant that influences vacuolar trafficking. Infect Immun 2007, 75:5575-5585.

70. McNamara PJ, Bradley GA, Songer JG: Targeted mutagenesis of the phospholipase $D$ gene results in decreased virulence of Corynebacterium pseudotuberculosis. Mol Microbiol 1994, 12:921-930.

71. Hinnebusch J, Cherepanov P, Du Y, Rudolph A, Dixon JD, Schwan T, Forsberg A: Murine toxin of Yersinia pestis shows phospholipase D activity but is not required for virulence in mice. Int J Med Microbio/ 2000, 290:483-487.

72. McKean SC, Davies JK, Moore RJ: Probing the heat shock response of Corynebacterium pseudotuberculosis: the major virulence factor, phospholipase D, is downregulated at 43 degrees C. Res Microbiol 2007, 158:279-286.

73. Mohan Das V, Ballal M: Proteinase and phospholipase activity as virulence factors in Candida species isolated from blood. Rev Iberoam Micol 2008, 25:208-210

74. Ponting CP, Kerr ID: A novel family of phospholipase D homologues that includes phospholipid synthases and putative endonucleases: identification of duplicated repeats and potential active site residues. Protein Sci 1996, 5:914-922.

75. McKean SC, Davies JK, Moore RJ: Expression of phospholipase D, the major virulence factor of Corynebacterium pseudotuberculosis, is regulated by multiple environmental factors and plays a role in macrophage death. Microbiology 2007, 153:2203-2211.

76. Kuhle K, Flieger A: Legionella phospholipases implicated in virulence. Curr Top Microbiol Immunol 2013, 376:175-209.

77. Whitworth T, Popov VL, Yu XJ, Walker DH, Bouyer DH: Expression of the Rickettsia prowazekii pld or tlyC gene in Salmonella enterica serovar Typhimurium mediates phagosomal escape. Infect Immun 2005, 73:6668-6673

78. Fevre C, Almeida AS, Taront S, Pedron T, Huerre M, Prevost MC, Kieusseian A, Cumano A, Brisse S, Sansonetti PJ, Tournebize R: A novel murine model of rhinoscleroma identifies Mikulicz cells, the disease signature, as IL-10 dependent derivatives of inflammatory monocytes. EMBO Mol Med 2013, 5:516-530.

79. Shibuya I, Miyazaki C, Ohta A: Alteration of phospholipid composition by combined defects in phosphatidylserine and cardiolipin synthases and physiological consequences in Escherichia coli. J Bacterio/ 1985 161:1086-1092.

80. Schlame M: Cardiolipin synthesis for the assembly of bacterial and mitochondrial membranes. J Lipid Res 2008, 49:1607-1620.

81. Ray NB, Durairaj L, Chen BB, McVerry BJ, Ryan AJ, Donahoe M, Waltenbaugh AK, O'Donnell CP, Henderson FC, Etscheidt CA, McCoy DM, Agassandian M, Hayes-Rowan EC, Coon TA, Butler PL, Gakhar L, Mathur SN, Sieren JC, Tyurina YY, Kagan VE, McLennan G, Mallampalli RK: Dynamic regulation of cardiolipin by the lipid pump Atp8b1 determines the severity of lung injury in experimental pneumonia. Nat Med 2010, 16:1120-1127.

82. Lopes SC, Neves CS, Eaton P, Gameiro P: Improved model systems for bacterial membranes from differing species: the importance of varying composition in PE/PG/cardiolipin ternary mixtures. Mol Membr Biol 2012, 29:207-217.

83. Russell AB, Leroux M, Hathazi $K$, Agnello DM, Ishikawa T, Wiggins PA, Wai SN, Mougous JD: Diverse type VI secretion phospholipases are functionally plastic antibacterial effectors. Nature 2013, 496:508-512.

84. Nagarajan N, Cook C, Di Bonaventura M, Ge H, Richards A, Bishop-Lilly KA, DeSalle R, Read TD, Pop M: Finishing genomes with limited resources: lessons from an ensemble of microbial genomes. BMC Genomics 2010, 11:242.

85. Frangeul L, Glaser P, Rusniok C, Buchrieser C, Duchaud E, Dehoux P, Kunst F: CAAT-Box, Contigs-Assembly and Annotation Tool-Box for genome sequencing projects. Bioinformatics 2004, 20:790-797.

86. Altschul SF, Madden TL, Schaffer AA, Zhang J, Zhang Z, Miller W, Lipman DJ: Gapped BLAST and PSI-BLAST: a new generation of protein database search programs. Nucleic Acids Res 1997, 25:3389-3402.

87. Bligh EG, Dyer WJ: A rapid method of total lipid extraction and purification. Can J Biochem Physiol 1959, 37:911-917.

88. Murdoch SL, Trunk K, English G, Fritsch MJ, Pourkarimi E, Coulthurst SJ: The opportunistic pathogen Serratia marcescens utilizes type VI secretion to target bacterial competitors. J Bacteriol 2011, 193:6057-6069.

doi:10.1186/1741-7007-12-41

Cite this article as: Lery et al:: Comparative analysis of Klebsiella pneumoniae genomes identifies a phospholipase D family protein as a novel virulence factor. BMC Biology 2014 12:41. 